\title{
Respiratory failure in a mouse model of myotonic dystrophy does not correlate with the CTG repeat length
} \author{
Ibtissam Barakat-Walter ${ }^{\mathrm{a}, \mathrm{b}, *}$ \\ a Department of Clinical Neurosciences, University Hospital, Lausanne, Switzerland \\ ${ }^{\mathrm{b}}$ Department of Fundamental Neurosciences, University of Lausanne, Switzerland \\ c Inserm, U781, Hôpital Necker-EM, Paris, France \\ ${ }^{\mathrm{d}}$ Université Paris Descartes-Sorbonne Paris Cité, Institut Imagine, Paris, France
}

Petrica-Adrian Panaite ${ }^{a}$, Thierry Kuntzer ${ }^{\mathrm{a}}$, Geneviève Gourdon ${ }^{\mathrm{c}, \mathrm{d}}$,

\section{A R T I C L E I N F O}

\section{Article history:}

Accepted 20 June 2013

\section{Keywords:}

Myotonic dystrophy type 1

Respiratory failure

DM1 transgenic mice

CTG trinucleotide

Pressure plethysmography

\begin{abstract}
A B S T R A C T
Myotonic dystrophy (DM1) is a multisystemic disease caused by an expansion of CTG repeats in the region of DMPK, the gene encoding DM protein kinase. The severity of muscle disability in DM1 correlates with the size of CTG expansion. As respiratory failure is one of the main causes of death in DM1, we investigated the correlation between respiratory impairment and size of the (CTG)n repeat in DM1 animal models. Using pressure plethysmography the respiratory function was assessed in control and transgenic mice carrying either 600 (DM600) or >1300 CTG repeats (DMSXL). The statistical analysis of respiratory parameters revealed that both DM1 transgenic mice sub-lines show respiratory impairment compared to control mice. In addition, there is no significant difference in breathing functions between the DM600 and DMSXL mice.

In conclusion, these results indicate that respiratory impairment is present in both transgenic mice sub-lines, but the severity of respiratory failure is not related to the size of the (CTG)n expansion.
\end{abstract}

(c) 2013 Elsevier B.V. All rights reserved.

\section{Introduction}

Myotonic dystrophy type 1 is one of the most common autosomal dominant muscular dystrophies and results from the expansion of a cytosine-thymine-guanine (CTG) nucleotide repeat, located in the $3^{\prime}$-untranslated region of the DMPK gene located on chromosome 19. Normal individuals have $\leq 30$ copies of this CTG repeat but in DM1 the number varies from 50 to $>3000$ (Brook et al., 1992; Fu et al., 1992; Harley et al., 1993; Mahadevan et al., 1992). Mildly affected, late-onset DM1 patients carry alleles with 50-150 repeats, while juvenile and adult-onset patients have 100-1000 CTG repeats (Hunter et al., 1992; Novelli et al., 1993). For unknown reasons, the mutation becomes unstable and the number of repeats tends to increase from generation to generation, accounting for genetic anticipation and the congenital DM form (CDM). Anticipation is a typical feature of DM1 and corresponds to the increasing severity in successive generations with earlier age at onset. Individuals with CDM can have more than one thousand repeats (Ashizawa et al., 1992; Lavedan et al., 1993; Mahadevan et al., 1992; Salehi et al., 2007; Tsilfidis et al., 1992).

\footnotetext{
* Corresponding author at: DNF, rue du Bugnon 9, 1005 Lausanne, Switzerland. Tel.: +412169251 28; fax: +41216925250.

E-mail address: Ibtissam.Walter@unil.ch (I. Barakat-Walter).
}

The main clinical manifestations of the juvenile and adult form of DM1 are muscle weakness and myotonia. CDM is characterized by a delay in skeletal muscle and brain development, muscular weakness and atrophy with hypotonia (Harper, 2001; Meola, 2000). Although DM1 is characterized mostly by muscle dysfunction, it is a multisystemic disease with various degrees of severity. Several clinical reports emphasized that acute and chronic respiratory failure is one of the major and potentially life-threatening features of DM1 patients. A transgenic mouse model of DM1 carrying a large CTG triplet expansion also shows respiratory impairment (Panaite et al., 2013). Genotype-phenotype correlation was reported in several studies (Gennarelli et al., 1996; Harley et al., 1993; Hunter et al., 1992; Jaspert et al., 1995; Novelli et al., 1993; Salehi et al., 2007), however, a systematic correlation between the size of CTG repeat and DM1 manifestations are debatable (Marchini et al., 2000). In the present study we investigate the relationship between the size of CTG repeat and the severity of the respiratory impairment by analysing breathings function in DM1 transgenic mice carrying either 600 or more than 1300 CTG repeats (Gomes-Pereira et al., 2007; Panaite et al., 2011; Seznec et al., 2000).

\section{Materials and methods}

All experimental protocols were reviewed and approved by the institutional animal care and use committee. 

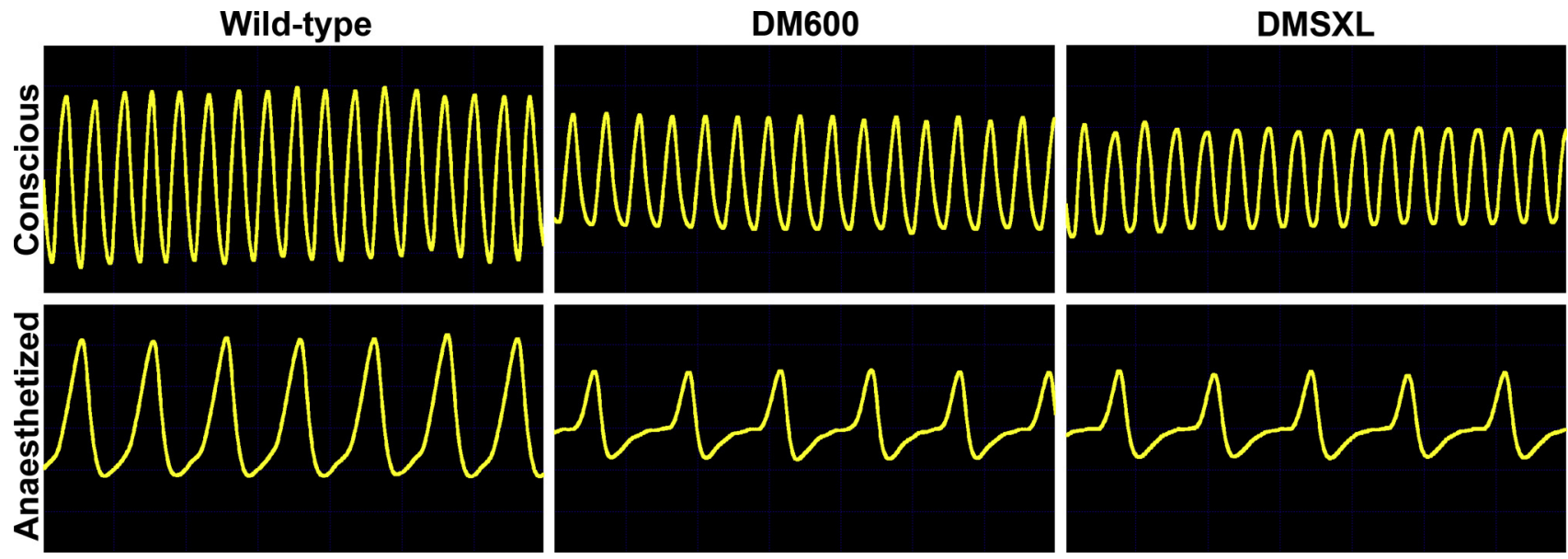

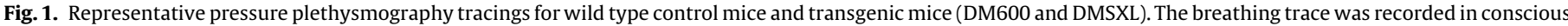

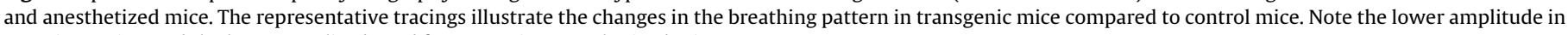
conscious mice, and the lower amplitude and frequency in anaesthetized mice.

\subsection{Generation of transgenic mouse models for DM1}

Transgenic mice carrying the human genomic DM1 region with an expanded repeat of approximately 600 CTG trinucleotides and displaying a mild DM1 phenotype have been described previously (Seznec et al., 2000). The mice were of mixed background (>90\% C57BL/6 background) and carried about 600 CTG repeats (DM600 mice). By breeding heterozygous mice, homozygous and wild type mice are obtained from the same litter. Recently, DMSXL mice carrying more than 1300 CTG repeats were obtained from DM600 mice after large expansions of the CTG repeat over successive generations (Gomes-Pereira et al., 2007). Expression of expanded CUG leads to the formation of numerous foci that colocalize with muscle-blind-like proteins 1 and 2 (MBNL1 and MBNL2) and are sequestered in the nuclei. Mild missplicing of target RNA is observed in muscle and heart tissue. The molecular features of DM1-associated RNA toxicity are associated with high mortality, growth retardation and muscle defects (abnormal histopathology, reduced muscle strength and lower motor performances) (Huguet et al., 2012). Only homozygous transgenic mice were used in our study since the heterozygous mice expressing a low level of DMPK transcripts have no obvious phenotype. Fifteen mice aged 5 months were analysed: 5 wild type control mice (body weight $33.8 \pm 3.6 \mathrm{~g}$ ); 5 DM600 transgenic mice (body weight $23.8 \pm 01.3 \mathrm{~g}$ ) and $5 \mathrm{DMSXL}$ transgenic mice (body weight $22.2 \pm 2.0 \mathrm{~g}$ ).

\subsection{Assessment of mice breathing function by pressure plethysmography}

Breathing function was assessed in wild type and transgenic mice (DM600 and DMSXL) by pressure plethysmography, a precise method adapted for both awake and anaesthetized small animals (Glaab et al., 2001; Stunden et al., 2001; Yilmaz et al., 2005). Briefly, each conscious mouse was firstly weighed then placed in a Respiromax cylindrical chamber (Respiromax system, Columbus Instruments, Columbus, OH, USA), while the head of the animal protruded through an inflatable latex cuff into the head-exposure chamber, which was ventilated by a continuous airflow. The animal was prevented from moving and held in position by shifting the tail rod. Each mouse was allowed to acclimatize to the plethysmography chamber for approximately $5 \mathrm{~min}$ before tests began. Throughout the testing period a sensitive transducer continuously measured the changes in pressure in the body chamber caused by the animal's respiration. Signals from the pressure transducer were amplified and digitized by an acquisition board on a computer. A respiratory function software (Columbus Instruments) displayed the graphic of the pressure variations, calculated the respiratory parameters and stored the data for subsequent statistical analysis. The following parameters were automatically calculated and analysed: tidal volume (TV, $\mathrm{ml}$ ), respiratory rate (RR, breaths per minutes) and minute volume (MV, tidal volume multiplied by respiratory rate, $\mathrm{ml} / \mathrm{min}$ ). In another series of experiments, respiratory function was measured in mice anaesthetized with isoflurane using a Matrx ${ }^{\mathrm{TM}}$ Quantiflex VMC ${ }^{\circledR}$ low flow anaesthesia system (Midmark, Versailles, OH, USA). Animals were placed individually in an induction chamber, and anaesthesia was induced with 5\% isoflurane in a gas mixture of $\mathrm{O}_{2} / \mathrm{N}_{2} \mathrm{O}_{2}(30 \% / 70 \%)$ which does not prevent spontaneous breathing. The animals were then quickly placed inside the Respiromax system, with a $1.5 \%$ isoflurane flow in the head chamber in the same $\mathrm{O}_{2} / \mathrm{N}_{2} \mathrm{O}_{2}$ gas mix. Animals were allowed to settle for $5 \mathrm{~min}$ before the first set of measurements. In all experiments the temperature of the body chamber was continuously monitored using a thermal probe. The following parameters were calculated and analysed: tidal volume (TV, $\mathrm{ml}$ ), respiratory rate (RR, breaths per minutes), minute volume ( $M V$, tidal volume multiplied by respiratory rate, $\mathrm{ml} / \mathrm{min}$ ). The respiratory function of each mouse was tested several times over a period of 2 weeks.

\subsection{Statistical analysis}

Values for all measurements were expressed as the mean \pm standard deviation (SD). Each respiratory parameter (TV, $\mathrm{RR}, \mathrm{MV}, \mathrm{MV} / \mathrm{g}$, heart rate, oxygen saturation) for each mouse was analysed and compared. ANOVA was used to determine significant differences between the groups, followed by Bonferonni-Holm post hoc test, and pair-groups were compared by Student's $t$-test. In all cases, plethysmograph data were normalized to the weight of the animal. Values are reported as mean \pm SD. $P<0.05$ was considered as a significant difference. All statistical analyses were performed using GraphPad Prism software (GraphPad Software Inc., La Jolla, CA, USA).

\section{Results}

To investigate whether the severity of respiratory problems is correlated with the size of the CTG triplet, we measured and compared, under the same experimental conditions, the respiratory 
Table 1

Mean values of respiratory parameters measured in anesthetized 5-6 months wild type and DM1 transgenic mice ( $n=5)$.

\begin{tabular}{|c|c|c|c|c|c|c|}
\hline Respiratory parameter & $\begin{array}{l}\text { Wild-type } \\
\mathrm{BW}=33.8 \pm 3.6 \mathrm{~g}\end{array}$ & $\begin{array}{l}\mathrm{DM} 600 \\
\mathrm{BW}=23.8 \pm 01.3 \mathrm{~g}\end{array}$ & $\begin{array}{l}\text { DMSXL } \\
\mathrm{BW}=22.2 \pm 2.0 \mathrm{~g}\end{array}$ & P1 & P2 & P3 \\
\hline RR & $125.7 \pm 14.4$ & $94.5 \pm 9.9$ & $87.8 \pm 5.3$ & $<0.01$ & $<0.01$ & ns \\
\hline $\mathrm{TV}(\mathrm{ml})$ & $0.381 \pm 0.041$ & $0.234 \pm 0.022$ & $0.228 \pm 0.013$ & $<0.01$ & $<0.01$ & ns \\
\hline $\mathrm{MV}(\mathrm{ml})$ & $47.72 \pm 11.01$ & $21.96 \pm 1.36$ & $20.48 \pm 1.33$ & $<0.01$ & $<0.01$ & ns \\
\hline TV/BW (ml/g) & $0.011 \pm 0.001$ & $0.010 \pm 0.002$ & $0.010 \pm 0.001$ & ns & ns & ns \\
\hline $\mathrm{MV} / \mathrm{BW}(\mathrm{ml} / \mathrm{g})$ & $1.4 \pm 0.17$ & $0.93 \pm 0.07$ & $0.94 \pm 0.09$ & $<0.01$ & $<0.01$ & ns \\
\hline
\end{tabular}

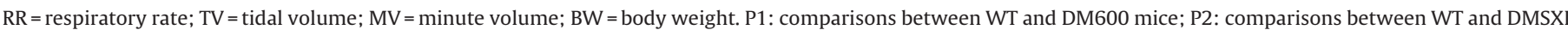
mice; P3: comparisons between DM600 and DMSXL mice; ns = non significant. $P<0.05$ was considered significant.

function in wild type control mice and in two transgenic mice sub-lines carrying either about 600 or more than 1300 CTG repeats.

First we assessed respiratory function in conscious mice. In all experiments we noticed that the breathing pattern recorded in conscious wild type control mice differed from that in both transgenic mice sub-lines (Fig. 1). Also, respiratory tracings in DM600 transgenic mice were comparable to those recorded in DMSXL mice. The statistical analysis of the most relevant respiratory parameters revealed that the mean values of the respiratory rate (RR), tidal volume (TV) and volume per minute (MV) were similar in both transgenic mice sub-lines, but were different from those measured in wild type control mice, which indicates a change in breathing function in transgenic mice.

During measurements we observed that conscious mice, specifically conscious transgenic mice, displayed a certain amount of agitation and stress which probably biased the evaluation of respiratory function in these mice. Therefore, the breathing function was assessed in anaesthetized mice. Under anaesthesia, the respiratory parameters measured over short and extended time periods provided reproducible values in all transgenic and control mice. The tracing of several repetitive measurements again showed that the respiratory pattern in both transgenic mice sub-lines was different (lower amplitudes and frequency) from that found in wild type control mice, but the breathing pattern was identical in DM600 and DMSXL mice (Fig. 1).

Detailed statistical analysis of the RR, TV, and MV demonstrated the presence of significant changes in respiratory function between the wild type control and transgenic mice sub-lines. Specifically, the RR, TV and MV were significantly decreased in both transgenic mice compared to wild type mice (Table 1 ). Consequently, the mean value for minute volume/body weight (Tidal volume $\mathrm{X}$ breathing frequency/body weight) was also reduced in DM600 and DMSXL mice. In addition, the statistical analysis confirmed the absence of a significant difference in the respiratory parameters between DM600 and DMSXL mice. The observed decrease in the RR, TV and MV in the both transgenic mice sub-lines indicated the presence of respiratory impairment in these mice.

\section{Discussion}

In DM1, the muscles, heart, brain, eye, endocrine, respiratory and gastroenteric systems are involved with variable levels of severity (Romeo, 2012). For example cataracts, cardiac conduction defects, respiratory failure, and changes in the CNS with mental retardation are recognized as common extramuscular manifestations in patients with DM1. Sleep disorders including excessive daytime sleepiness and nocturnal respiratory events are also prominent in patients affected by DM1. Sleep disturbances have repeatedly been reported as one of the earliest symptoms of DM1 and may represent a marker of central nervous system neurodegenerative processes in DM1 (Laberge et al., 2004, 2013; Phillips et al., 1999; Romigi et al., 2011). An abnormal expanded CTG trinucleotide repeat in the 3 -untranslated region of the myotonic dystrophy protein kinase (DMPK) gene is the genetic basis for
DM1 (Fu et al., 1992; Mahadevan et al., 1992). Over a threshold of between 40 and 50 CTG repeat nucleotides, the mutation becomes unstable and after three to four generations the CTG repeat can become very long, leading to the congenital form of the disease when transmitted by the mother (Ashizawa et al., 1992; Harley et al., 1993; Lavedan et al., 1993; Tsilfidis et al., 1992). Although the muscular disability becomes more severe and frequent in the CDM patients, the severity of other manifestations of the disease is still a debatable issue (Botta et al., 2008; Gennarelli et al., 1996; Jaspert et al., 1995; Marchini et al., 2000; Novelli et al., 1993; Perini et al., 1999; Winblad et al., 2006). In fact, genotype-phenotype correlation studies have reported a relationship between the size of the CTG repeat in lymphocyte DNA and the severity of muscular disability as well as nervous system and gonadal dysfunction (Jaspert et al., 1995; Kinoshita and Hirose, 1999; Logigian et al., 2004). An association between the CTG repeat size and cognitive impairment has also been described (Sistiaga et al., 2010; Winblad et al., 2006). A relation between the severity of cardiac arrhythmia as well as conduction abnormalities and CTG repeat length has been noticed in DM1 patients (Finsterer et al., 2001). Furthermore, another study has concluded that measurement of triplet expansions in patients' lymphocyte DNA is highly valuable and accurate for prognostic assessment (Gennarelli et al., 1996). While these studies support the presence of a correlation between the severity of certain DM1 features and the size of CTG triplet, other studies have shown controversial results. The clinical examination of 24 DM1 patients aged between 18 and 64 years old from 14 unrelated families showed that respiratory insufficiency, diabetes and cataract were not related to the size of the CTG repeat detected in blood cells (Marchini et al., 2000). Also, analysing CTG repeats and electrocardiographic recordings in the same DM1 patients revealed no correlation between the repeat number and cardiac abnormalities (Rakocevic-Stojanovic et al., 2003). In addition, no significant correlation was found between the severity of sleep disorders and genetic size of CTG repeat (Laberge et al., 2004; Marchini et al., 2000; Romigi et al., 2011). Recent results of an extensive genotypephenotype study performed on 2650 patients have emphasized that great care should be taken in inferring too much from the leucocyte CTG repeat number in a clinical diagnostic prediction (Salehi et al., 2007). Therefore, the correlation between the size of CTG repeat and DM1 manifestations is still unclear.

Clinically respiratory and cardiac problems have long been recognized as the main complications of DM1 patients. Large cohort studies have reported that in adult onset DM1 respiratory problems are the leading causes of death (around 40\%) (de Die-Smulders et al., 1998; Groh et al., 2008; Mathieu et al., 1999). In the CDM, only $50 \%$ of patients survive to their mid 30 s and the death of about $66 \%$ of surviving patients is due to respiratory causes (Reardon et al., 1993). As the correlation between genotype and respiratory problems has remained unclear, we set out in the present study to measure and compare the breathing functions in two DM1 transgenic mouse sub-lines: (i) DM600 transgenic mice carrying about 600 CTG triplet and displaying a mild DM1 phenotype (Seznec et al., 2000); (ii) DMSXL mice having a large number of CTG 
trinucleotide repeats (>1300) and expressing a more severe muscular disability demonstrated by the formation of numerous nuclear foci that colocalize with muscleblind-like protein 1 and 2 (MBNL1 and MBNL2), mild missplicing of target RNA in muscle and heart tissue, high mortality, growth retardation and muscle and brain defects (Gomes-Pereira et al., 2007; Hernandez-Hernandez et al., 2013; Huguet et al., 2012; Panaite et al., 2011; Reardon et al., 1993). The results of our present study revealed two important points: (i) the presence of respiratory impairment in DM600 mice as well as in DMSXL mice; (ii) the respiratory deficiency does not become more severe in DMSXL mice which have a larger number of CTG repeats. The two transgenic mice sub-lines display equal respiratory impairment characterized by a significant decrease in the most relevant respiratory parameters compared to control animals. The respiratory impairment detected in DM1 transgenic mice is not caused by their small weight as previously we have shown that control mice with similar size and weight to DM1 mice do not show respiratory failure (Panaite et al., 2013). The absence of a significant difference in breathing parameters between DM600 and DMSXL mice is in line with our previous morphological and morphometric results (Panaite et al., 2008, 2013). Indeed, similar pathological changes in diaphragmatic neuromuscular junctions (NMJs) and phrenic nerves were detected in both DM600 and DMSXL mice compared to control mice. In both transgenic mice sub-lines a denervation rate of about $20 \%$ of the end-plates (EPs) was calculated and an identical reduction in the size, shape complexity and density of acetylcholine receptors in EPs was measured. In addition, a loss of about $40 \%$ of the number of unmyelinated phrenic afferents was observed in both DM600 and DMSXL transgenic mice (Panaite et al., 2008, 2013). In conclusion, the DM600 and DMSXL mice have a similar respiratory failure indicating that there is no relationship between the severity of the respiratory problems assessed in these mice and the size of CTG triplet. This is consistent with some clinical studies reporting that the respiratory and cardiac insufficiency is not related to the number of CTG repeats detected in blood cells of DM1 patients. The examination of 24 DM1 subjects having a variable number of CTG repeats (50-2200) demonstrated that respiratory failure is present in DM1 patients with small numbers of CTG repeats as well as in patients with higher numbers of repeats. Moreover, the respiratory impairment does not become more severe in patients with large CTG expansions (Marchini et al., 2000; Rakocevic-Stojanovic et al., 2003). The authors emphasize that the severity of single, but not all DM1 clinical manifestations may correlate with the size of CTG triplet in peripheral blood cells. To explain why the size of CTG repeats correlates with the severity of some but not all DM1 clinical manifestations, several mechanisms are suggested. Among the mechanisms that could be involved in this phenomenon is the reduction in the expression of genes neighbouring the amplified CTG repeat or sequestration of nuclear CUG binding proteins (Marchini et al., 2000). Moreover, nuclear accumulations of toxic expanded DMPK gene may be responsible for aberrant genes expression in modifying alternative splicing in brain/brainstem (Laberge et al., 2013). Another mechanism is the somatic mosaicim with different amplification rates in the various tissues (Jaspert et al., 1995). It is probable that in DM1 animal model one or all these mechanisms may play a role.

\section{Conclusions}

The measurement of respiratory function in DM1 transgenic mice carrying either 600 or more than 1300 CTG repeats showed that the respiratory impairment is present in both transgenic mice sub-lines. In addition the respiratory failure does not become more severe in transgenic mice harbouring a greater number of CTG repeats. These results show that in the DM1 animal model there is no correlation between the severity of respiratory impairment and the size of CTG triplet. The fact that DM1 transgenic mice demonstrate, as patients with DM1, that muscle damage but not respiratory failure is correlated to CTG expansion size, provides further evidence of the validity of the DM1 animal model which can be used to study different mechanisms underlying DM1.

\section{Acknowledgements}

This work was supported by the "Association Française contre les Myopathies" (grant \# 15644 awarded to I.B.W). Authors wish to thank Dr. M. Price for critical reading of the manuscript.

\section{References}

Ashizawa, T., Dubel, J.R., Dunne, P.W., Dunne, C.J., Fu, Y.H., Pizzuti, A., Caskey, C.T., Boerwinkle, E., Perryman, M.B., Epstein, H.F., 1992. Anticipation in myotonic dystrophy. II. Complex relationships between clinical findings and structure of the GCT repeat. Neurology 42, 1877-1883.

Botta, A., Rinaldi, F., Catalli, C., Vergani, L., Bonifazi, E., Romeo, V., Loro, E., Viola, A. Angelini, C., Novelli, G., 2008. The CTG repeat expansion size correlates with the splicing defects observed in muscles from myotonic dystrophy type 1 patients. Journal of Medical Genetics 45, 639-646.

Brook, J.D., McCurrach, M.E., Harley, H.G., Buckler, A.J., Church, D., Aburatani, H., Hunter, K., Stanton, V.P., Thirion, J.P., Hudson, T., 1992. Molecular basis of myotonic dystrophy: expansion of a trinucleotide (CTG) repeat at the $3^{\prime}$ end of a transcript encoding a protein kinase family member. Cell 68, 799-808.

de Die-Smulders, C.E., Howeler, C.J., Thijs, C., Mirandolle, J.F., Anten, H.B., Smeets, H.J., Chandler, K.E., Geraedts, J.P., 1998. Age and causes of death in adult-onset myotonic dystrophy. Brain 121, 1557-1563.

Finsterer, J., Gharehbaghi-Schnell, E., Stollberger, C., Fheodoroff, K., Seiser, A., 2001. Relation of cardiac abnormalities and CTG-repeat size in myotonic dystrophy. Clinical Genetics 59, 350-355.

Fu, Y.H., Pizzuti, A., Fenwick Jr., R.G., King, J., Rajnarayan, S., Dunne, P.W., Dubel, J., Nasser, G.A., Ashizawa, T., de, J.P., 1992. An unstable triplet repeat in a gene related to myotonic muscular dystrophy. Science 255, 1256-1258.

Gennarelli, M., Novelli, G., Andreasi, B.F., Martorell, L., Cornet, M., Menegazzo, E., Mostacciuolo, M.L., Martinez, J.M., Angelini, C., Pizzuti, A., Baiget, M., Dallapiccola, B., 1996. Prediction of myotonic dystrophy clinical severity based on the number of intragenic [CTG]n trinucleotide repeats. American Journal of Medical Genetics 65, 342-347.

Glaab, T., Daser, A., Braun, A., Neuhaus-Steinmetz, U., Fabel, H., Alarie, Y., Renz, H., 2001. Tidal midexpiratory flow as a measure of airway hyperresponsiveness in allergic mice. American Journal of Physiology. Lung Cellular and Molecular Physiology 280, L565-L573.

Gomes-Pereira, M., Foiry, L., Nicole, A., Huguet, A., Junien, C., Munnich, A., Gourdon, G., 2007. CTG trinucleotide repeat "big jumps": large expansions, small mice. PLoS Genetics 3, e52.

Groh, W.J., Groh, M.R., Saha, C., Kincaid, J.C., Simmons, Z., Ciafaloni, E., Pourmand, R., Otten, R.F., Bhakta, D., Nair, G.V., Marashdeh, M.M., Zipes, D.P., Pascuzzi, R.M., 2008. Electrocardiographic abnormalities and sudden death in myotonic dystrophy type 1. New England Journal of Medicine 358, 2688-2697.

Harley, H.G., Rundle, S.A., MacMillan, J.C., Myring, J., Brook, J.D., Crow, S., Reardon, W., Fenton, I., Shaw, D.J., Harper, P.S., 1993. Size of the unstable CTG repeat sequence in relation to phenotype and parental transmission in myotonic dystrophy. American Journal of Human Genetics 52, 1164-1174.

Harper, P.S., 2001. Myotonic Dystrophy, 3rd ed. Saunders WB, London.

Hernandez-Hernandez, O., Guiraud-Dogan, C., Sicot, G., Huguet, A., Luilier, S., Steidl, E., Saenger, S., Marciniak, E., Obriot, H., Chevarin, C., Nicole, A., Revillod, L., Charizanis, K., Lee, K.Y., Suzuki, Y., Kimura, T., Matsuura, T., Cisneros, B., Swanson, M.S., Trovero, F., Buisson, B., Bizot, J.C., Hamon, M., Humez, S., Bassez, G., Metzger, F., Buee, L., Munnich, A., Sergeant, N., Gourdon, G., Gomes-Pereira, M., 2013. Myotonic dystrophy CTG expansion affects synaptic vesicle proteins, neurotransmission and mouse behaviour. Brain 136, 957-970.

Huguet, A., Medja, F., Nicole, A., Vignaud, A., Guiraud-Dogan, C., Ferry, A., Decostre, V., Hogrel, J.Y., Metzger, F., Hoeflich, A., Baraibar, M., Gomes-Pereira, M., Puymirat, J., Bassez, G., Furling, D., Munnich, A., Gourdon, G., 2012. Molecular, physiological, and motor performance defects in DMSXL mice carrying $>1,000$ CTG repeats from the human DM1 locus. PLoS Genetics 8, e1003043.

Hunter, A., Tsilfidis, C., Mettler, G., Jacob, P., Mahadevan, M., Surh, L., Korneluk, R., 1992. The correlation of age of onset with CTG trinucleotide repeat amplification in myotonic dystrophy. Journal of Medical Genetics 29, 774-779.

Jaspert, A., Fahsold, R., Grehl, H., Claus, D., 1995. Myotonic dystrophy: correlation of clinical symptoms with the size of the CTG trinucleotide repeat. Journal of Neurology 242, 99-104.

Kinoshita, M., Hirose, K., 1999. Correlation between CTG triplet repeat length and the extent of multisystesmic disorders in myotonic dystrophy. Nihon Rinsho. Japanese Journal of Clinical Medicine 57, 917-926.

Laberge, L., Begin, P., Montplaisir, J., Mathieu, J., 2004. Sleep complaints in patients with myotonic dystrophy. Journal of Sleep Research 13, 95-100. 
Laberge, L., Gagnon, C., Dauvilliers, Y., 2013. Daytime sleepiness and myotonic dystrophy. Current Neurology and Neuroscience Reports 13, 340.

Lavedan, C., Hofmann-Radvanyi, H., Shelbourne, P., Rabes, J.P., Duros, C., Savoy, D., Dehaupas, I., Luce, S., Johnson, K., Junien, C., 1993. Myotonic dystrophy: size- and sex-dependent dynamics of CTG meiotic instability, and somatic mosaicism. American Journal of Human Genetics 52, 875-883.

Logigian, E.L., Moxley, R.T., Blood, C.L., Barbieri, C.A., Martens, W.B., Wiegner, A.W. Thornton, C.A., Moxley III, R.T., 2004. Leukocyte CTG repeat length correlates with severity of myotonia in myotonic dystrophy type 1. Neurology 62, 1081-1089.

Mahadevan, M., Tsilfidis, C., Sabourin, L., Shutler, G., Amemiya, C., Jansen, G., Neville C., Narang, M., Barcelo, J., O'Hoy, K., 1992. Myotonic dystrophy mutation: an unstable CTG repeat in the 3' untranslated region of the gene. Science 255, 1253-1255.

Marchini, C., Lonigro, R., Verriello, L., Pellizzari, L., Bergonzi, P., Damante, G., 2000. Correlations between individual clinical manifestations and CTG repeat amplification in myotonic dystrophy. Clinical Genetics 57, 74-82.

Mathieu, J., Allard, P., Potvin, L., Prevost, C., Begin, P., 1999. A 10-year study of mortality in a cohort of patients with myotonic dystrophy. Neurology 52, 1658-1662.

Meola, G., 2000. Clinical and genetic heterogeneity in myotonic dystrophies. Muscle and Nerve 23, 1789-1799.

Novelli, G., Gennarelli, M., Menegazzo, E., Mostacciuolo, M.L., Pizzuti, A., Fattorini, C., Tessarolo, D., Tomelleri, G., Giacanelli, M., Danieli, G.A., 1993. (CTG)n triplet mutation and phenotype manifestations in myotonic dystrophy patients. Biochemical Medicine and Metabolic Biology 50, 85-92.

Panaite, P.A., Gantelet, E., Kraftsik, R., Gourdon, G., Kuntzer, T., Barakat-Walter, I., 2008. Myotonic dystrophy transgenic mice exhibit pathologic abnormalities in diaphragm neuromuscular junctions and phrenic nerves. Journal of Neuropathology and Experimental Neurology 67, 763-772.

Panaite, P.A., Kielar, M., Kraftsik, R., Gourdon, G., Kuntzer, T., Barakat-Walter, I., 2011. Peripheral neuropathy is linked to a severe form of myotonic dystrophy in transgenic mice. Journal of Neuropathology and Experimental Neurology 70, 678-685.

Panaite, P.A., Kuntzer, T., Gourdon, G., Lobrinus, J.A., Barakat-Walter, I., 2013. Functional and histopathological identification of the respiratory failure in a DMSXL transgenic mouse model of myotonic dystrophy. Disease Models \& Mechanisms 6, 622-631.

Perini, G.I., Menegazzo, E., Ermani, M., Zara, M., Gemma, A., Ferruzza, E., Gennarelli, M., Angelini, C., 1999. Cognitive impairment and (CTG)n expansion in myotonic dystrophy patients. Biological Psychiatry 46, 425-431.
Phillips, M.F., Steer, H.M., Soldan, J.R., Wiles, C.M., Harper, P.S., 1999. Daytime somnolence in myotonic dystrophy. Journal of Neurology 246, 275-282.

Rakocevic-Stojanovic, V., Savic, D., Pavlovic, S., Lavrnic, D., Romac, S., Apostolski, S. 2003. Correlation between cardiac involvement and CTG repeat amplification in myotonic dystrophy type 1 . Acta Myologica 22, 26-27.

Reardon, W., Newcombe, R., Fenton, I., Sibert, J., Harper, P.S., 1993. The natural his tory of congenital myotonic dystrophy: mortality and long term clinical aspects. Archives of Disease in Childhood 68, 177-181.

Romeo, V., 2012. Myotonic dystrophy type 1 or Steinert's disease. Advances in Experimental Medicine and Biology 724, 239-257.

Romigi, A., Izzi, F., Pisani, V., Placidi, F., Pisani, L.R., Marciani, M.G., Corte, F., Panico, M.B., Torelli, F., Uasone, E., Vitrani, G., Albanese, M., Massa, R., 2011. Sleep disorders in adult-onset myotonic dystrophy type 1: a controlled polysomnographic study. European Journal of Neurology 18, 1139-1145.

Salehi, L.B., Bonifazi, E., Stasio, E.D., Gennarelli, M., Botta, A., Vallo, L., Iraci, R., Massa R., Antonini, G., Angelini, C., Novelli, G., 2007. Risk prediction for clinical phenotype in myotonic dystrophy type 1: data from 2,650 patients. Genetic Testing 11, 84-90.

Seznec, H., Lia-Baldini, A.S., Duros, C., Fouquet, C., Lacroix, C., Hofmann-Radvanyi, H., Junien, C., Gourdon, G., 2000. Transgenic mice carrying large human genomic sequences with expanded CTG repeat mimic closely the DM CTG repeat intergenerational and somatic instability. Human Molecular Genetics 9, 1185-1194.

Sistiaga, A., Urreta, I., Jodar, M., Cobo, A.M., Emparanza, J., Otaegui, D., Poza J.J., Merino, J.J., Imaz, H., Marti-Masso, J.F., Lopez de, M.A., 2010. Cognitive/personality pattern and triplet expansion size in adult myotonic dystrophy type 1 (DM1): CTG repeats, cognition and personality in DM1. Psychologica Medicine 40, 487-495.

Stunden, C.E., Filosa, J.A., Garcia, A.J., Dean, J.B., Putnam, R.W., 2001. Development of in vivo ventilatory and single chemosensitive neuron responses to hypercapnia in rats. Respiration Physiology 127, 135-155.

Tsilfidis, C., MacKenzie, A.E., Mettler, G., Barcelo, J., Korneluk, R.G., 1992. Correlation between CTG trinucleotide repeat length and frequency of severe congenital myotonic dystrophy. Nature Genetics 1, 192-195.

Winblad, S., Lindberg, C., Hansen, S., 2006. Cognitive deficits and CTG repeat expansion size in classical myotonic dystrophy type 1 (DM1). Behavioral and Brain Functions 2, 16

Yilmaz, C., Johnson Jr., R.L., Hsia, C.C., 2005. A rebreathing method for measuring lung volume, diffusing capacity and cardiac output in conscious small animals. Respiratory Physiology \& Neurobiology 146, 215-223. 